\title{
À la recherche des caractéristiques chinoises
}

\section{Approches thérapeutiques occidentales dans la République populaire de Chine}

\author{
Annette Hillers-Chen \\ Psychotherapie-Wissenschaft 8 (2) 192018 \\ www.psychotherapie-wissenschaft.info \\ CC BY-NC-ND \\ https://doi.org/10.30820/8243.02
}

Mots-clés : Psychothérapie, caractéristiques chinoises, mise en culture, République populaire de Chine

La psychothérapie est devenue dans la République populaire de Chine un marché florissant et concurrentiel. Avec peu d'exceptions indigènes, la plupart des procédés sont importés de la sphère culturelle " occidentale ». Dans l'état actuel de la psychothérapie, il est à peine possible de décider quelles approches se seraient imposées ou s'adapteraient mieux ou moins bien à la Chine. Les débats sur l'adaptation s'étendent d'une complète incompatibilité jusqu'à l'applicabilité universelle et les arguments les plus courants concernant la nécessité de l'adaptation reposent sur des dichotomies abstraites ou sur les trois classiques Confucianisme, Taoïsme et Bouddhisme.

La structure d'aujourd'hui complexe, changeant à un rythme rapide de la Chine peut toutefois de moins en moins être décrite avec de telles déclarations de généralisation. Les questions sur ce qu'est en réalité " chinois " sont certes un élément important de la recherche intrachinoise d'identité, mais en raison de l'interdépendance de ceux qui s'interrogent et de l'interprétation concrète, la question des " caractéristiques chinoises " mène à l'absurde : Les expériences concrètes ne correspondent plus aux acceptations théoriques simplificatrices sur " la » culture chinoise ; des réalités, comme les effets visibles du socialisme en tant que doctrine de l'État, sont masqués.

Une issue concernant le discours sur des caractéristiques particulières de formes de psychothérapie en Chine réside dans un dialogue approfondi, qui met davantage en avant les complexités et cela d'une façon systématique et sur la base des expériences de terrain. La recherche commune sur la façon dont il est possible d'aborder des phénomènes concrets peut constituer la pierre angulaire du développement de la psychothérapie en elle-même. Cela ne signifie toutefois pas une adaptation unilatérale d'une forme de thérapie à la Chine et pour la Chine en particulier, mais une mise et une remise en culture réciproques, à savoir une modification progressive d'une forme de thérapie dans son ensemble, dans le processus du Se Heurter Ensemble, l'Un à l'Autre. La question sur les caractéristiques chinoises devient ici secondaire.

\section{L'auteure}

Annette Hillers-Chen est Professeure Associée de Psychologie Appliquée et conseillère psychothérapeutique au Centre d'Éducation et de Recherche Sanitaires à l'Université de Nanjing. Elle travaille sur le domaine thématique de l'acculturation en Chine et a créé une sinocoopération avec l'Institut de Gestaltthérapie Intégrative de Würzburg depuis 2009.

\section{Contact}

Nanjing University

School for Social and Behavioral Sciences

Department of Psychology

Xianlin Campus

Heren Lou \#315

Postal code: 210046

hillerschen@nju.edu.cn 